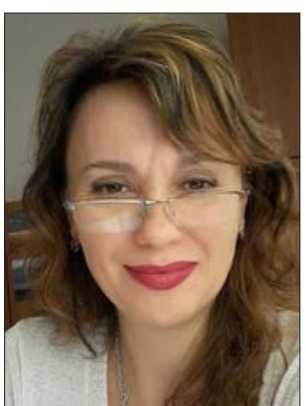

Alla V. Bondar Бондар Алла Віталіївна
УДК 005.8

\section{SUBSTANTIATION OF THE BASIC CATEGORIES OF ENERGY ENTROPY THEORY OF ORGANIZATIONS}

\section{ОБҐРУНТУВАННЯ ОСНОВНИХ КАТЕГОРІЙ EHEPГOEHTPOПIЙНОÏ TЕОРIÏ ОРГАНІЗАЦІЙ}

DOI https://doi.org/10.15589/smi2020.1(13).4

Alla V. Bondar

Бондар Алла Віталіївна, канд. техн. наук

ocheretyankaalla@gmail.com

ORCID: 0000-0003-2228-2726

Odessa National Maritime University, Odessa

Одеський національний морський університет, м. Одеса

Abstract. Aim. The purpose of the study is to specify the content and formalize the main categories of energy-entropy theory of the organization. Intuitive understanding and recognition of the fact of entropy organization in the energy context is peculiarity of many modern specialists. In the research there is a conceptual presentation of ideas and patterns without presenting specific formalizations for the evaluation and study of organizations' energy. Methodology. In order to achieve this goal, the basic principles of the first beginning of thermodynamics and the laws of energy entropy are used. Results. The study found that the approaches used in thermodynamics and statistical physics could not be applied to study the energy entropy of organizations. Therefore, the main categories of thermodynamics were substantiated and analytically expressed in the work, taking into account the specificity of organizations: energy, temperature, work, entropy and heat. It is accepted that from the point of view of the organization, energy is a universal measure of the diversity of resources of the organization (protoenergy) and its information-material-energy exchange with the external environment. Work within the framework of the energy-entropy theory of an organization is the energy obtained as a result of the activity of the organization and realization of the manufactured product, taking into account the corresponding energy costs. In this case, "work", as a category in thermodynamics, should be useful, everything else is dissipation. Heat is a waste of energy that does not provide direct useful work and an increase in internal energy. Under the temperature of an organization refers to the ratio of its relative effectiveness with existing capabilities, whereby, at absolute temperature entropy tends to a minimum. Scientific novelty. Thus, within the framework of this study have been formulated at a substantive level and formalized the main categories of energy-entropy theory of organizations. The mathematical representation for energy entropy obtained is based on the use of information entropy as an indicator of the "order" of the structures of the organization. Practical importance. The research forms a new perspective on the processes of functioning and development of organizations and provides opportunities to identify new sources for improving the efficiency of these processes. A further development of the presented results is an analysis of the behavior of energy entropy in dynamics.

Key words: energy entropy, organization energy, work, entropy, temperature, heat.

Анотація. Метою дослідження є конкретизація змісту і формалізація основних категорій енергоентропійної теорії організації. Інтуїтивне розуміння і визнання факту існування організації ентропії в енергетичному контексті притаманне багатьом сучасним фахівцям. У дослідженнях має місце концептуальна подача ідеї та закономірностей без представлення конкретних формалізацій для оцінки і вивчення енергоентропії організацій. Методика. Для досягнення мети в роботі використані основні положення першого початку термодинаміки та закони енергоентропіки. Результати. У ході дослідження виявлено, що підходи, які використовуються в термодинаміці та статистичній фізиці, потребують певної модифікації для вивчення енергоентропії організацій. Тому в роботі були обгрунтовані й аналітично виражені основні категорії термодинаміки з урахуванням специфіки організацій: енергія, температура, робота, ентропія і теплота. Прийнято, що з погляду організації, енергія - це універсальна міра різноманітності ресурсів організації (протоенергіiі) та іiі інформаційно-речовинно-енергетичного обміну із зовнішнім середовищем. «Робота» в рамках енергоентропійної теорії організації - це енергія, 
отримана внаслідок активності організації та реалізації виробленого продукту, з урахуванням відповідних енергетичних витрат. «Робота» як категорія з термодинаміки повинна бути корисною, все інше - це дисипація. «Теплота» - це витрачена енергія, яка не забезпечує безпосередню корисну роботу і приріст внутрішньої енергії. Під «температурою» організації розуміється співвідношення ііі відносної ефективності з наявними можливостями. Наукова новизна. У рамках нашого дослідження визначені на змістовному рівні та виражені формалізовано основні категорії енергоентропійної теорії організацій. Отримане математичне уявлення для енергоентропії засноване на використанні інформаційної ентропії як показника «порядку» збудованих структур організації. Практична значимість. Дослідження формує новий погляд на процеси функціонування та розвитку організацій і надає можливості до виявлення нових джерел підвищення ефективності цих процесів. Подальше вивчення представлених результатів полягає в аналізі поведінки енергоентропії в динаміці.

Ключові слова: енергоентропіка, енергія організації, робота, ентропія, температура, теплота.

\section{References}

[1] Alekseyev, G.N. (1983). Energoentropika [Energyentropics]. Moskva: Znaniye. [in Russian]

[2] Averin, G.V. (2014). Sistemodinamika: monografiya [Systemodynamics: monograph]. Donetsk: Donbass. [in Russian]

[3] Bushuev, S.D., Lisitsyn, A.B., Timinsky, A.G. (2008). Information model of organizational management system. Project management and development of virology, 2 (26), 20-29.

[4] Averin, G.V., Zvyagintseva, A.V. (2016). O vzaimosvyazi statisticheskoy i informatsionnoy entropii pri opisanii sostoyaniy slozhnykh sistem [On the relationship of statistical and informational entropy in describing the states of complex systems]. Nauchnyye vedomosti Belgorodskogo gosudarstvennogo universiteta. Seriya: Matematika. Fizika, T. 44, 20 (241), 105-116. [in Russian]

[5] Averin, G.V., Zvyagintseva, A.V. (2013). Vzaimosvyaz' termodinamicheskoy i informatsionnoy entropii pri opisanii sostoyaniy ideal'nogo gaza [Interrelation of thermodynamic and informational entropy in the description of ideal gas states]. Sistemnyy analiz i informatsionnyye tekhnologii v naukakh o prirode i obshchestve, 1-2, 26-37. [in Russian]

[6] Petrenko, A.V. Upravleniye organizatsiyey kak bor'ba s entropiyey [Management of the organization as a struggle with entropy]. Institutsional'nyy repozitoriy Natsional'nogo Aviatsionnogo Universiteta Ukrainy. URL: https:www. er.nau.edu.ua/bitstream/NAU/14626/1/Entropy.pdf [in Russian]

[7] Stefancić, H., Žebec, M.S. and Perackovic, K. (2000). Approach to a quantitative description of social systems based on thermodynamic formalism, Eniropy, 2, 98-105.

[8] Stepanić, Josip. (2004) Social equivalent of free energy. Interdisciplinary Description of Complex Systems: INDECS 2.1. 53-60.

[9] Likhonosova G.S. (2018). Yentropiyne balansuvannya: instrument usunennya sotsial'no-yekonomichnogo vidtorgnennya na pidpriêmstvi [Entropy balance: a tool for the consolidation of social and economic trade]. Chasopis yekonomichnikh reform, 2, 43-51. [in Ukrainian]

[10] Bondar, A., Bushuyev, S., Onyshchenko, S., Hiroshi, H. (2020). Entropy Paradigm of Project-Oriented Organizations Management . Proceedings of the 1st International Workshop IT Project Management (ITPM 2020) Vol. 1. Lviv, Ukraine, February 18-20, 2020, CEUR Workshop Proceedings (CEUR-WS.org), 233-243. URL: http://ceur-ws.org/ Vol-2565/paper20.pdf.

[11] Onyshshenko, S., Bondar, A., Andrievska, V., Sudnyk, N., Lohinov, O. (2019). Constructing and exploring the model to form the road map of enterprise development. Eastern-European Journal of Enterprise Technologies, 5, 3 (101), 33-42. URL: https://doi.org/10.15587/1729-4061.2019.179185.

[12] Bondar', A.V., Onyshchenko, S.P. (2019). Optimizatsiya vremennykh parametrov proyekta [Optimization of project time parameters]. Upravlinnya rozvitkom skladnikh sistem, 39, 11-18. URL: https://doi.org/10.6084/ M9.FIGSHARE.11340629.V1 [in Russian]

[13] Bondar, A.V. (2019). Kontseptsiya tsinnosti lyuds'kikh resursiv proyektno-orientovanoi organizatsii [The concept of the human resources value of a project-oriented organization]. Zbirnik naukovikh prats ' NUK, 1, $135-141$. URL: https://doi.org/10.15589/znp2019.1(475).19 [in Ukrainian]

[14] Dulesov, A.S., Semenova, M.Yu. (2012). Sub'yektivnaya veroyatnost' v opredelenii mery neopredelennosti sostoyaniya ob'yekta [Subjective probability in determining the measure of the uncertainty of the state of an object] Fundamental'nyye issledovaniya, 3, 81-86. [in Russian]

Постановка проблеми. Універсальність першого початку термодинаміки (енергетичного балансу) привела до застосування такої специфічної категорії, як «ентропія» в дослідженнях біологічних і соціальних систем. Енергоентропіка [1] як універсальна па- радигма вивчення навколишнього світу стає основою для багатьох наукових публікацій.

Впродовж останнього десятиріччя термодинамічна ентропія стала розглядатися і в рамках теорії організацій. Як преамбулу цього дослідження наве- 
демо цитату [2, с. 91]: «Останнім часом 3'явилося багато робіт, де термодинамічні ідеї формально переносяться у сферу соціології, економіки, екології і т. п. Обгрунтування цих підходів зустрічає серйозні ідейні та логічні труднощі. У багатьох нефізичних науках обсяг експериментальних даних не дає можливості провести узагальнення на феноменологічному рівні, а побудова математичних теорій «буксує» ще на етапі вироблення загальних понять, висновків і закономірностей. Однак процес конвергенції наук вже йде, i термодинамічний метод є одним $з$ основних універсальних методів побудови теорій».

Аналіз останніх досліджень і публікацій. На відміну від інформаційної ентропії, за своєю суттю пов'язаною з невизначеністю, яка досить добре вкладається в уявлення про функціонування і розвиток систем різної природи (наприклад, [3]), фізична категорія тільки «приміряється» на системи нефізичної природи.

У [4] на базі певної аксіоматики теоретично доводиться існування ентропії як характеристичної функції простору станів системи: «Якщо існує доведений факт того, що для деякої системи можна висунути гіпотезу існування емпіричної міри як деякої величини, яка комплексно характеризує стан системи, то можливе обгрунтування принципу існування певного виду ентропії та встановлення закономірностей, які характеризують зміну станів цієї системи» [4, с. 110]. У роботі [5] ці ж автори роблять висновок про те, що такий підхід може бути «розповсюджений на системи нефізичної природи, наприклад, природні, соціальні й економічні».

Крім того, для будь-якої системи має місце інформаційно-енергетичний обмін із зовнішнім середовищем, що призводить до якоїсь інтеграції «енергетичної ентропії» та «інформаційної ентропії», й окремі автори (наприклад, [1]), вважають, що загальна ентропія будь-якої системи (зокрема підприємства) є сумою зазначених ентропій. Можливо, це і так, але сьогодні немає чіткого обгрунтування цієї тези.

Інтуїтивне розуміння і визнання факту існування організації ентропії в енергетичному контексті притаманне багатьом сучасним фахівцям. I, зокрема, в роботі [6] дається логічне обгрунтування фактів наявності ентропії та ілюстрації іiї динаміки. Автор наводить досить переконливі та зрозумілі приклади «роботи» законів енергоентропіки для підприємств, сформульованих в [1], але без будьякої їх формалізації.

Цікавими є роботи $[7 ; 8]$, де на рівні концепції представлені такі поняття, як температура й ентропія соціальної системи. Також слід відзначити роботу [9], в якій автор використовує енергоентропію як ступінь відторгнення підприємства. Проте незрозумілим залишається те, як же автори в зазначених джерелах пропонують вимірювати рівні температури й ентропії.

Виокремлення не вирішених раніше частин загальної проблеми. Таким чином, має місце кон- цептуальна подача ідеї та закономірностей без представлення конкретних формалізацій для оцінки та дослідження енергоентропії організацій.

Таке застосування ентропії в дослідженнях, присвячених управлінню соціальними, економічними, соціально-економічними та соціотехнічними системами, пояснюється становленням енергоентропійної теорії організацій як нового напряму і відповідає сценарію розвитку будь-якої нової наукової думки.

У [10] представлена енергоентропійна концепція організації, в рамках якої обгрунтований взаємозв'язок структурної, інформаційної та енергетичної ентропії. Наша праця розвиває висловлені у [10] ідеї й основні положення.

Метою дослідження $є$ конкретизація змісту i формалізація основних категорій енергоентропйної теорії організації.

Основний матеріал (результати). Енергоентропійна концепція будується на специфічних постулатах, які приймаються аксіоматично і $є$ основою для формування відповідних закономірностей.

Крім того, для організацій практично неможливе відтворення одних і тих самих умов: «Не можна увійти в одну річку двічі» Геракліта тут більш ніж доречне. Крім того, що зовнішнє середовище організації динамічно або навіть турбулентно змінюється, всередині самої організації люди - як основний драйвер організації - змінюються, набуваючи досвіду, втрачаючи і набуваючи певні навички і т. п. Дотримання у процесі спостереження / експерименту кількісних характеристик ресурсів не забезпечить ïx якісну однорідність. Тобто говорити про чистоту будь-якого експерименту в рамках управління організацією неможливо, тому що практично будь-яка статистика буде неоднорідною через: а) динаміку зовнішнього середовища; б) якісну зміну внутрішнього середовища організації.

Таким чином, підходи, які використовуються в термодинаміці та статистичній фізиці, потребують певної модифікації для вивчення енергоентропії організацій. Тому обгрунтуємо й аналітично висловимо основні категорії термодинаміки з урахуванням специфіки організацій.

Отже, в термодинаміці основними категоріями $є$ : енергія - $U$, температура $-T$, робота $-W$, ентропія $-S$, теплота $-Q$.

Ентропія - це міра знецінення енергії, тобто іiі «марне» (неефективне) витрачання (відповідно до $[1 ; 9 ; 10])$. У термодинаміці енергія $U$ спрямовується на здійснення роботи $W$, але частина ії у вигляді теплоти передається зовнішньому середовищу, що і породжує дисипацію енергії. Причому існує певний взаємозв'язок між кількістю теплоти $Q$ і температурою $T$.

Енергія. Ресурси виступають як аналог енергії. Такий підхід використовується в усіх сучасних роботах цього напряму (наприклад, [9; 10]). В окремих публікаціях автори використовують термін «квазіенергія» в контексті того, що ресурси - це не «енергія» в 
теперішньому її розумінні, а (відповідно до значення «квазі») несправжня енергія, майже енергія, псевдоенергія. Такий підхід є, безумовно, правильним, 3 урахуванням сутності енергії як того, що перетворюється в роботу. В [8] автор вважає, що відповідним показником вимірювання квазіенергії $є$ вартість трансформації одного виду капіталу в інший.

Дійсно, якщо організація використовує людські ресурси у процесі виробництва, то це не означає, що ці ресурси безпосередньо перетворюються в роботу. Це означає, що в роботу перетворюються знання, вміння, досвід і компетентність персоналу. Тому людський ресурс є «протоенергією» (proto-; від protos - перший, первинний). А ось для організації грошовий еквівалент використання знань, умінь, досвіду і компетентності персоналу і є витраченою «енергією».

Таким чином, із погляду організації, енергія - це грошові кошти, універсальна міра різноманітності ресурсів організації (протоенергіï) та іiі інформаційно-матеріально-енергетичного обміну із зовнішнім середовищем. Тому надалі використовуватимемо саме таке розуміння енергії організації.

Ресурси організації спрямовані на здійснення роботи. У найпростішому варіанті розгляду сутності «роботи» для організації як виконання іiї основної функції (наприклад, із виробництва якогось продукту), результатом роботи є «продукт», за який організація отримує грошову виручку. Дотримуючись вищенаведених міркувань, продукт організації також є протоенергією, а грошові надходження за реалізований товар формують енергію. Таким чином, протоенергія як ресурсів, так і продукту «генерує» енергію.

Отже, у організації можуть бути виділені різні види ресурсів, із яких можна сформувати дві категорії. Перша - це «активи» організації у вигляді будівель, споруд, обладнання тощо, так звані матеріально-речові ресурси. Друга категорія - це трудові (людські) ресурси. У цьому дослідженні не акцентується увага на класифікації ресурсів. 3 погляду мети дослідження важливою є наявність ресурсів (протоенергіï), які формують капітал організації, та ресурсів (протоенергії), що витрачаються у процесі функціонування організації. Вважаємо, що можна виділити $n$ типів протоенергії / ресурсів організації і, відповідно, їх кількість за типами:

$$
E^{p}=\left(E_{1}^{p}, E_{2}^{p}, \ldots, E_{n}^{p}\right) .
$$

Компоненти (2) $E_{i}^{p}, i=\overline{1, n}$ є кількісними, а не вартісними характеристиками ресурсів. Загальна енергія (капітал) організації:

$$
U=\sum_{i=1}^{n} l_{i} \cdot E_{i}^{p},
$$

де $l_{i}, i=\overline{1, n}$ коефіцієнти приведення різних видів протоенергії до єдиного оціночного показника, у нашому випадку - до грошових одиниць.
Після випуску продукту (протоенергіi) у кількості:

$$
W^{p}=W^{p}\left(E_{1}^{p}, E_{2}^{p}, \ldots, E_{n}^{p}\right)
$$

організація отримує відповідний вхідний потік енергії $E^{\text {in }}$, який $є$ певною функцією від кількості продукту $W^{p}$ з одного боку, і ресурсів організації $E_{1}^{p}, E_{2}^{p}, \ldots, E_{n}^{p}$, з іншого. Вхідний потік енергії організації $E^{\text {in }}$ формується із вхідного потоку енергії від реалізації продукту $E_{p r}^{\text {in }}\left(W^{p}\right)$ і вхідного потоку від інших видів діяльності (наприклад, здачі приміщень / обладнання в оренду і т. п.) $E_{o}^{\text {in }}$ :

$$
\begin{aligned}
& E^{i n}=E_{o}^{i n}+E_{p r}^{i n}\left(W^{p}\right)=E_{o}^{i n}+E_{p r}^{i n}\left(W^{p}\left(E_{1}^{p}, E_{2}^{p}, \ldots, E_{n}^{p}\right)\right)= \\
& =E_{o}^{i n}+E_{p r}^{\text {in }}\left(E_{1}^{p}, E_{2}^{p}, \ldots, E_{n}^{p}\right)=E^{i n}\left(E_{1}^{p}, E_{2}^{p}, \ldots, E_{n}^{p}\right) .
\end{aligned}
$$

3 огляду на універсальність грошової форми подання ресурсів (3) і (4) трансформуються в:

$$
\begin{gathered}
W^{p}=W^{p}(U)=W^{\prime p}\left(E^{e x}\right), \\
E^{i n}=E_{o}^{i n}+E_{p r}^{i n}\left(W^{p}\right)=E_{o}^{i n}+E_{p r}^{i n}\left(W^{p}(U)\right)= \\
=E_{o}^{i n}+E_{p r}^{i n}\left(W^{\prime p}\left(E^{e x}\right)\right)=E_{o}^{i n}+E_{p r}^{\prime i n}(U)=E_{s}^{\text {in }}\left(E^{e x}\right)=E_{s}^{i n}(U) .
\end{gathered}
$$

Наведені міркування демонструють те, що залежно від мети енергія, що входить, може бути представлена як у вигляді функції від продукту $W^{p}$, так i у вигляді функції від капіталу $U$ або ресурсів, які витрачаються.

Слід зазначити, що функції в (4), (6) не є лінійними функціями відповідно до загальних закономірностей, властивих економіці [11; 12].

На базі (5) може бути виконаний аналіз, результати якого дозволять зробити висновки про частку (i, відповідно, ролі) окремих видів діяльності в загальній структурі діяльностей організації. Крім того, якщо організація виробляє кілька видів продуктів, то це може бути відображено у (5) і також піддається аналізу.

Робота. Робота в термодинаміці підлягає певному виміру, заснованому на зміні параметрів системи (наприклад, зміні обсягу газу або переміщенні об'єкта у просторі і т. д.). Робота організації та кожного іiі підрозділу також може бути виміряна, і варіантів вимірювання того, що організації виконала, можна навести багато.

Але, з погляду енергоентропійної концепції, робота, яку організація «виконувала», і фактично корисна робота, котру вона «виконала», можуть істотно відрізнятися. Пояснімо це твердження і почнемо із прикладу. Нехай організація у процесі виробництва продукту продемонструвала досить високі показники, наприклад, була досягнута певна економія ресурсів, собівартість продукції вийшла значно нижчою, ніж це було раніше, і т. п. Тобто можна, з одного боку, стверджувати, що організація працювала ефективно, але «щось пішло не так», і вироблений продукт не був реалізований у запланованій кількості, тобто організація практично не отримала необхідної виручки (припливу енергіi) за свою виконану роботу. 
Питання: чи можна той продукт, який справила організація, вважати «роботою»? 3 погляду енергоентропійної концепції - НІ. «Робота» як категорія термодинаміки повинна бути корисною, все інше це дисипація.

Такий розгляд є справедливим, оскільки завданням дослідження є визначення принципу формування і закономірності поведінки ентропії, пов'язаної 3 витрачанням енергії не на роботу і приріст енергії, тобто енергію, яка не формує безпосередньо благо для організації.

У процесі роботи організація збільшує свій запас енергії, тобто поповнює $U$ на величину $\varnothing U$. Згідно 3 формулюванням першого закону енергоентропіки [1]:

$$
U=A+\Delta U+Q
$$

де $Q$ - теплота. На цьому етапі дослідження не будемо розмежовувати роботу і приріст внутрішньої енергії, розглядаючи їх у сукупності як єдину величину $W=A+\Delta U$, яка формується внаслідок життєдіяльності організації.

Таким чином, робота організації (корисна робота) $A$ в сукупності із приростом енергії дорівнює різниці між вхідною та вихідною енергією:

$$
W=A+\Delta U=E^{i n}-E^{e x} .
$$

Отже, робота в рамках енергоентропійної теорії організації - це енергія, отримана у процесі діяльності організації та реалізації виробленого продукту з урахуванням відповідних енергетичних витрат.

Теплота. Організація повинна витрачати певні ресурси на підтримку власної структури двох видів - внутрішньої та зовнішньої. Зовнішня структура є частиною зовнішнього середовища, нерозривно пов'язаною з організацією насамперед енергетично. Наприклад, практично кожна комерційна організація реалізує рекламні заходи, спрямовані як на підтримку попиту (тобто на утримання споживачів), так і на його збільшення (залучення нових споживачів). Сучасному бізнесу притаманна така його організація, за якої збудовані відносини зі споживачами підтримуються і розвиваються [13].

Оскільки «теплота» - це витрачена енергія, яка не забезпечує безпосередньо корисну роботу і приріст внутрішньої енергії, то $Q$ може бути виражено як:

$$
Q=U-W=U-\left(E^{i n}-E^{e x}\right)
$$

Tемпература. Незважаючи на те, що окремі автори вводять таку категорію, як «температура» для підприємств і організацій, ніхто з них не пропонує конкретного інструменту її вимірювання. За мінімальної ентропії стан системи наближається до еталонного / ідеального. Таким чином, необхідно визначити, що слід розуміти під «температурою організації» і що ж для організації слід вважати «ідеальним» станом.

Під температурою організації будемо розуміти співвідношення іiї відносної ефективності з наявни- ми можливостями, тобто за температуру приймемо величину:

$$
T=\frac{\mu}{H},
$$

де $\propto-$ показник відносної ефективності організації в контексті порівняння досягнутої ефективності 3 якимось еталонним значенням, $H$-інформаційна ентропія.

Показник ефективності організації порівняно 3 еталонною ефективністю:

$$
\begin{gathered}
\mu=\frac{\eta}{\eta^{*}}, \\
\eta=\frac{U-E^{e x}+E^{i n}}{U},
\end{gathered}
$$

$\eta^{*}$ - показник ефективності еталонного стану, $\eta$ - показник ефективності, який відображає «віддачу» від сумарної енергії організації у вигляді приросту енергії $E^{\text {in }}-E^{e x}$. Відзначимо, що у (12) у знаменнику використовується сумарна енергія організації. Навіть якщо частина фінансових ресурсів організації використовується у вигляді заощаджень і не спрямована безпосередньо на виробництво продукту, ці ресурси повинні все одно служити протоенергією і генерувати приплив енергії, наприклад, у вигляді відсотків за банківський депозит і т. п. Якщо в організації є приміщення / обладнання, яке також не використовується для виробничих цілей, то ці приміщення / обладнання слід здати в оренду або знайти їм альтернативне застосування 3 метою отримання припливу енергії від їх використання. В іншому разі зазначені ресурси (протоенергія) є «замороженими» і не виконують роботу на благо організації.

Що слід прийняти за показник ідеальної ефективності $\eta^{*}$ ?

У подібній ситуації можна використовувати два підходи:

- перший підхід передбачає, що ідеальний стан - це той, який планує (бажає досягти) організація. I тут можливі варіанти, виходячи із принципів планування;

згідно із другим підходом ідеальний стан це якийсь «еталонний» стан, за який можуть бути прийняті, наприклад, кращі в галузі показники.

$H$ відображає рівень інформаційної ентропії організації, яка оцінює можливі варіанти стану організації:

$$
H=-\sum_{k=1}^{K} p\left(A_{k}\right) \cdot \ln \left(p\left(A_{k}\right)\right),
$$

$A_{k}$ - варіанти стану організації, $p\left(A_{k}\right)$ - вірогідності цих станів. Як показники стану організації приймемо $A_{k}=\left(E_{k}^{\text {in }}, E_{k}^{e x}\right), k=\overline{1, K}$, оскільки саме ці показники при заданому рівні $U$ для організації відображають результати ііі діяльності й ефективність енергообігу.

Енергоентропія. Згідно з енергетичним балансом (7) і сутністю теплоти: 


$$
Q=S \cdot T,
$$

де $S, T$, відповідно, - енергоентропія і температура.

3 урахуванням (10) - (14) вираз для ентропії набуде вигляду:

$$
S=\frac{U-\left(E^{i n}-E^{e x}\right)}{T}=\frac{\left(U-\left(E^{i n}-E^{e x}\right) \cdot U \cdot \eta^{*} \cdot H\right.}{U-E^{e x}+E^{i n}} .
$$

Проілюструємо ці міркування прикладом. Нехай у організації структура зв'язків із зовнішнім середовищем досить впорядкована і вибудувана таким чином, що ця організація може розраховувати з великою ймовірністю на певний рівень припливу енергії $E^{\text {in }}$ при заданому $E^{e x}$ . I, навпаки, якщо у структурах організації панує хаос, то варіантів прогнозних значень $E^{\text {in }}$ може бути значна кількість. Причому виділення варіантів із достатньо високою ймовірністю практично неможливо.

У першій ситуації організація має, наприклад, такий розподіл $E^{\text {in }}$ :

$$
\begin{array}{ccccc}
E_{1}^{i n} & E_{2}^{i n} & E_{3}^{i n} & E_{4}^{i n} & E_{5}^{i n} \\
0,05 & 0,05 & 0,8 & 0,05 & 0,05
\end{array} .
$$

У другій ситуації:

$$
\begin{array}{llllllll}
E_{1}^{i n} & E_{2}^{i n} & E_{3}^{i n} & E_{4}^{i n} & E_{5}^{i n} & E_{6}^{i n} & E_{7}^{i n} & E_{8}^{i n} \\
0,2 & 0,1 & 0,1 & 0,1 & 0,1 & 0,2 & 0,1 & 0,1
\end{array} .
$$

Інформаційна ентропія в першому випадку складає $H=0,777$, у другому $-H=2,025$.
У [14] міститься теза про те, що інформаційна ентропія - «це усунена невизначеність для досягнення мети». Таким чином, максимальне зниження інформаційної ентропії дозволяє організації забезпечити таке функціонування, за якого $E^{e x}$ стає практично достовірною на етапі планування інформаційноенергетично-речового обміну із зовнішнім середовищем.

Наприклад, організація може направляти значні суми на маркетинг, але не отримувати очікувану віддачу, тому витрачена енергія перетворюється в цьому разі на теплоту. Або ще один приклад. Організація правильно вибудувала відносини зі споживачами, і iї «зовнішня структура» функціонуе ефективно - маркетинг забезпечує поставлені цілі. Але персонал організації надлишковий, і більша його частина працює не ефективно, тому внутрішня структура організації «поглинає» ефективну роботу зовнішньої структури, перетворюючи витрачену енергію на теплоту.

Висновки. У межах нашого дослідження визначені на змістовому рівні та виражені формалізовано основні категорії енергоентропійної теорії організацій: енергії, роботи, теплоти, температури, енергоентропії. Отримане математичне уявлення для енергоентропії засноване на використанні інформаційної ентропії як показника «порядку» збудованих структур організації. Таким чином пов'язані «порядок» $\mathrm{i}$ дисипація енергії в організації.

Подальше вивчення представлених результатів полягає в аналізі поведінки енергоентропії в динаміці.

\section{Список літератури:}

[1] Алексеев Г.Н. Энергоэнтропика. Москва : Знание, 1983. 268 с.

[2] Аверин Г.В. Системодинамика : монография. Донецк : Донбасс, 2014. 405 с.

[3] Bushuev, S.D., Lisitsyn, A.B., Timinsky, A.G. Information model of organizational management system. Project management and development of virology. 2008. № 2 (26). P. 20-29.

[4] Аверин Г.В., Звягинцева А.В. О взаимосвязи статистической и информационной энтропии при описании состояний сложных систем. Научные ведомости Белгородского государственного университета. Серия : Математика. Физика. 2016. Т. 44. № 20 (241). С. 105-116.

[5] Аверин Г.В., Звягинцева А.В. Взаимосвязь термодинамической и информационной энтропии при описании состояний идеального газа. Системный анализ и информационные технологии в науках о природе и обществе. 2013. № 1-2. С. 26-37.

[6] Петренко А.В. Управление организацией как борьба с энтропией. Институииональный репозиторий Национального Авиаиионного Университета Украины. URL: www.er.nau.edu.ua/bitstream/NAU/14626/1/Entropy.pdf.

[7] Stefancić, H., Žebec, M.S. and Perackovic, K. Approach to a quantitative description of social systems based on thermodynamic formalism. Eniropy. 2000. Vol. 2. P. 98-105.

[8] Stepanić, Josip. Social equivalent of free energy. Interdisciplinary Description of Complex Systems: INDECS 2.1. 2004. P. 53-60.

[9] Ліхоносова Г.С. Ентропійне балансування: інструмент усунення соціально-економічного відторгнення на підприємстві. Часопис економічних реформ. 2018. № 2. С. 43-51.

[10] Bondar A., Bushuyev S., Onyshchenko S., Hiroshi H. Entropy Paradigm of Project-Oriented Organizations Management. Proceedings of the 1st International Workshop IT Project Management (ITPM 2020). Vol. 1. Lviv, Ukraine, February 18-20, 2020, CEUR Workshop Proceedings (CEUR-WS.org), 2020. P. 233-243. URL: http://ceur-ws.org/ Vol-2565/paper20.pdf.

[11] Onyshchenko S., Bondar A., Andrievska V., Sudnyk N., Lohinov O. Constructing and exploring the model to form the road map of enterprise development. Eastern-European Journal of Enterprise Technologies. 2019. Vol. 5. № 3 (101). P. 33-42. URL: https://doi.org/10.15587/1729-4061.2019.179185. 
[12] Бондарь А.В., Онищенко С.П. Оптимизация временных параметров проекта. Управління розвитком складних систем. 2019. № 39. С. 11-18. URL: https://doi.org/10.6084/M9.FIGSHARE.11340629.V1.

[13] Bondar, A.V. The concept of the human resources value of a project-oriented organization. Proceedings of Admiral Makarov NUS. 2019. № 1. P. 135-141. URL: https://doi.org/10.15589/znp2019.1(475).19.

[14] Дулесов А.С., Семенова М.Ю. Субъективная вероятность в определении меры неопределенности состояния объекта. Фундаментальные исследования. 2012. № 3. С. 81-86.

(C) Бондар А. В. Дата надходження статті до редакції: 18.05.2020 Дата затвердження статті до друку: 27.07.2020 